\title{
Considerations on a Scientist's Academic Mission and Roles in a Higher Education School
}

\author{
Vilma Žydžiūnaitè - Ilona Tandžegolskienè - \\ Ausra Rutkiene $\dot{e}^{*}$
}

\begin{abstract}
Analysis of the scientific literature has shown that the mission of a scientist is inherent to an individual and is oriented towards institution and activity or performance being implemented in higher education. Every higher education school defines its mission and vision, thus the aim of a scientist is to act according to the provided institutional mission. Academic staff at higher education schools, according to the attributed roles, performs various activities which are associated with teaching and research, administration and human resources management, work in labour services. According to the roles and activities being distinguished and described, diverging concepts exist for handling the academic staff roles. The aim of conceptual research refers to consideration and description of a scientist's missions and roles in higher education generally and a higher education school specifically. The answers to the following research questions are provided in the article: What are the levels of a scientist missions in higher education? How the roles of a scientist could be defined in higher education referring to autonomy or interdependence? What competencies are attributed to the roles of a scientist in higher education? The research concludes that the mission of a scientist is related to the multi-layered concept covering the roles, context, organizational structure and values in a higher education institution. It is essential for a scientist to perceive and define their own mission(s), role(s), responsibilities and obligations to a higher education school, students, science, and society. The mission of a scientist in a higher education school rests in certain combination of diverse competencies being applied on both organizational
\end{abstract}

\footnotetext{
*Vilma Žydžiūnaitè, Vytautas Magnus University, Kaunas, Lithuania; v.zydziunaite@smf.vdu.It

Ilona Tandžegolskienè, Vytautas Magnus University, Kaunas, Lithuania; i.tandzegolskiene@smf.vdu.lt

Ausra Rutkienè, Vytautas Magnus University, Kaunas, Lithuania; a.rutkiene@smf.vdu.lt
} 


\title{
Acta Technologica Dubnicae \\ volume 5, 2015, issue 2
}

\begin{abstract}
and individual levels. In summary, academic staff roles are entwined and contrasting with each other. However, the roles of a researcher and a teacher are linked in general as the role of a teacher requires accomplishing academic staff activities such as planning learning activities, devoting time to consultations, meetings and discussions with students.
\end{abstract}

Key words: competence, higher education, mission, researcher, role, scientist, teacher.

\section{Introduction}

Research relevance. It is important to stress that in many cases a mission is defined and described as external activity from "outside", which is determined by an institution in which a person works. The analysed dictionaries define "mission" as a task, job, duty or commission, which is given to a person or a group of people to meet a specific task, purpose or aims. In this case, it is not a choice, but assigned function or functions. A "mission" is also associated with the activities or tasks carried out. Dictionaries indicate that a "mission" may be accomplished in a foreign country where a person is referred to for a specific identifiable purpose. A "mission" correlates with a group of persons assigned a diplomatic post in a foreign country (Collins English Dictionary, 2005; Random House Kernerman Webster's College Dictionary, 2010; Dicionary.com, 2015) or conduct negotiations (Random House Kernerman Webster's College Dictionary, 2010; Merriam-Webster Dictionary, 2015; Dicionary.com, 2015; The Free Dictionary by Farlex, 2015), technical or scientific attentions (Merriam-Webster Dictionary, 2015; Dicionary.com, 2015), networking (Random House Kernerman Webster's College Dictionary, 2010; Merriam-Webster Dictionary, 2015; Dicionary.com, 2015; The Free Dictionary by Farlex, 2015), performance of religious (Random House Kernerman Webster's College Dictionary, 2010; Dicionary.com, 2015; Collins English Dictionary, 2005) and social (Dicionary.com, 2015; The Free Dictionary by Farlex, 2015), medical (The Free Dictionary by Farlex, 2015) and educational (The Free Dictionary by Farlex, 2015) assistance, and evangelism (Random House Kernerman Webster's College Dictionary, 2010; Dicionary.com, 2015; The Free Dictionary by Farlex, 2015). In the social sphere, a mission can be equated with calling or personal beliefs (Merriam-Webster Dictionary, 2015; Dicionary.com, 2015) by identifying the church, evangelical or philanthropic organization as a sender or an intermediary. The diplomatic activity distinguishes embassies abroad in regard to the performance of a "mission" (Random House Kernerman Webster's College Dictionary, 2010). Macmillan Dictionary (2015) distinguishes cultural, factfinding or rescue missions. Some dictionaries describe a mission as a personal inclination or calling for certain activities. This is associated with business and activities implemented not only in the professional field (Collins English 


\section{Acta Technologica Dubnicae \\ volume 5, 2015, issue 2}

Dictionary, 2005; Dicionary.com, 2015). The definition of a mission often describes the state of experienced strong inner feeling, ambition or vocation (Oxford Advanced Learner's Dictionary, 2015). Another description of this term is related to the inner belief that a mission is a particular practice and a personal obligation (Merriam-Webster Dictionary, 2015). The mission of business is defined as a group responsibility (Merriam-Webster Dictionary, 2015; Dicionary.com, 2015; The Free Dictionary by Farlex, 2015).

The mission can be identified by physical location or district (Dicionary.com, 2015), or buildings (Dicionary.com, 2015) where the missionary activities are conducted. A mission is defined as a diplomatic mission abroad (The Free Dictionary by Farlex, 2015). A mission can be defined as a group of persons or delegates in a particular event (The Free Dictionary by Farlex, 2015).

Military, marine and aerospace speech names "mission" as the operational task that is required to meet (Dicionary.com, 2015). In some cases, a mission treated as intended activity may be a part of a program, for example, the mission "Mars" (The Free Dictionary by Farlex, 2015). A mission is often described as a task when higher rank officers provide instructions for lower rank persons or group of persons (Cambridge Advanced Learners Dictionary \& Thesaurus, 2015). In social welfare a mission is known as charity or support centre, offering shelter, assistance or support to the poor (Collins English Dictionary, 2005). Exclusive South Africa's mission is defined as a long and complex process (Collins English Dictionary, 2005; Dicionary.com, 2015).

In summary, a mission can be considered as belonging to an external function or/and a task order. A mission is associated with tasks, performed activities and very often with obligations, orders in foreign countries. A mission can be defined as a person's predisposition, vocation, inner experience, ambition referring to the certain activities aimed specifically at him/her. A mission can be defined as a personal or group responsibility in business (Collins English Dictionary, 2005).

Review of academic staff roles in a higher education school traditionally leads to the three distinguished positions of a teacher, researcher and administrator or service staff (Enders \& Teichler, 1997; Kreber, 2000; Gordon, 2003; Houston et al., 2006; Siegel et al, 2007; Schlüter \& Winde, 2009). There are many indications in the scientific literature emphasizing a number of roles that academic staff representative may respond to at the same time. For example, a professor of a higher education school can be a lecturer/teacher and researcher, too, and these roles may be accompanied by other roles such as a Dean of the Faculty, a Senate member and/or the head of a higher education school (Enders \& Teichler, 1997; Schlüter \& Winde, 2009).

The adjustment of previously mentioned main roles reflects the traditional academic career (Siegel et al., 2007). However, Houston et al. (2006) emphasizes that the most important roles going side by side are those two of a teacher and researcher. Still, researchers emphasize that academic staff has to 


\section{Acta Technologica Dubnicae \\ volume 5, 2015, issue 2}

perform the additional roles of an administrator and service provider at the same time. Another group of authors (Rowley, 1996; Enders, 1998; Cummings, 2009; Bloch et al., 2012) distinguishes the same main roles of a teacher and researcher describing them as classic and primary, nevertheless, other presumable roles are not mentioned in scientific discussions. The literature also distinguishes the roles of a manager (Rowley, 1996; Arimato, 2009; Klug, 2010), a tutor (Rowley, 1996; Wilcox et al., 2005; Senger, 2009), a supervisor (Boudon, 2006) and a leader (Boudon, 2006; Conrad, 2006). Literature review findings have shown that the authors (Conrad, 1998; Boudon, 2006; Siegel et al., 2007; Arimoto, 2009) identify the roles of academic staff through performed activities, namely, researchers' roles of leaders and supervisors (Conrad, 1998; Boudon, 2006) are not mentioned directly though being revealed due to the performed activities.

The performance or activities of a scientist, as well as training for most postgraduate scientists, start - and too often end - in the laboratory, despite the fact that due to the shortage of senior university posts many of them will need to deploy their skills elsewhere. With today's emphasis on obtaining funding, the main focus of universities refers to achieving "the high research ratings" due to research publications in premier league journals. This is not a negative objective, but in the working process a scientist receives scant attention despite the perceived and performed missions and roles, or prepared $\mathrm{PhD}$. students and postdoctoral workers for careers outside academia. Extensive training and gained experience should help to fit scientists' roles outside the mainstream research. The role of a scientist in the society should be emphasized, as well as their mission and role should be therefore related to the interpretation of evidence and bringing perspective, particularly where there is a body of evidence pointing in a different direction (Elves, 2013). It would be of benefit if the concepts such as a scientists' mission(s) and role(s) could be applied more widely in policy-making strategies in higher education, $\mathrm{PhD}$. training and meaningful research execution in general.

The adequate research questions were the following: What are the levels of a scientist missions in higher education? How the roles of a scientist could be defined in higher education referring to autonomy or interdependence? What competencies are attributed to the roles of a scientist in higher education?

The aim of conceptual research refers to consideration and description of a scientist's missions and roles in higher education generally and a higher education school specifically.

The provided article is conceptual in its scientific nature and the method of literature being applied as the type of literature was chosen with purpose. The "literature review" was applied to analyse conceptually and thematically the concepts of a "mission" and "role" of a scientist in higher education school, and narrate the descriptive text. The literature review for the research has covered a wide range of concepts and subjects at various levels, completeness and comprehensiveness (Grant \& Booth, 2009). In the article, the terms "researcher", 


\section{Acta Technologica Dubnicae \\ volume 5, 2015, issue 2}

"scientist", "scholar" or "professor" were not differentiated according to their semantic, content or institutional position/status meaning. All those terms were used alternately with the general reference to "an academic" being mostly referred to as "a scientist".

\section{Mission(s) of a scientist in higher education: levels}

Analysis of scientific literature has shown that the mission of a scientist is inherent to an individual and is oriented towards an institution and activity or performance being implemented in higher education. Every higher education school defines its mission and vision, thus the aim of a scientist is to act according to the provided institutional mission. Therefore, statement of the mission, as well as interfaces and compliance with the activities refer to the scientific research objects.

A scientist or researcher in higher education is an acting person who must implement the mission being formulated by a higher education institution. Therefore, it makes sense to analyse the considerations on description of higher education schools' missions in order to define a scientist's mission in higher education more accurately (see Figure 1).

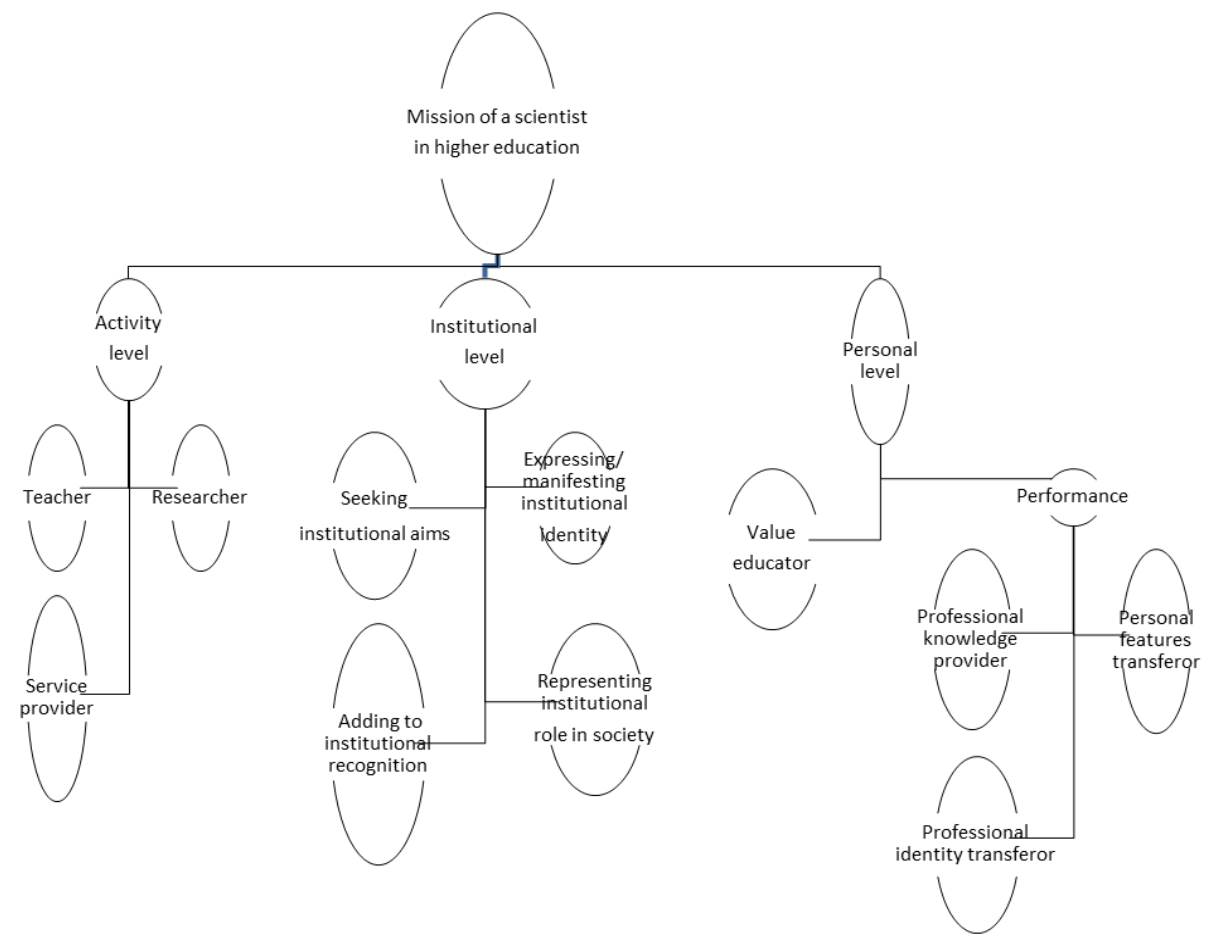

Figure 1. Levels of a scientist's mission in higher education 


\section{Acta Technologica Dubnicae \\ volume 5, 2015, issue 2}

Activity level. The academic mission of a higher education school includes a number of activity spheres. The activities of a higher education school might be unsteady and constantly improved in order to ensure the continuity of teaching and research (Brinley, 2012). Teaching in higher education schools covers the main and traditional mission (Howell \& Karimbux, 2004) or activities designed to ensure highly qualified training services (Joiner et al., 2008). Thus, a scientist's missions by acting or operating at a higher education school is to provide teaching, adult education and continuing training (Feldner, 2006; Keyser, 2004). However, teaching in a higher education school is associated with granting of knowledge, and thus is also seen as the educational mission being relevant to political decisions within education (Joiner et al., 2008). Education and training of intellectuals are singled out as the component of the teaching mission of a higher education school (Tarquinio et al., 2003; Keyser, 2004).

Scientists in higher education schools carry out another mission of a researcher which refers to scientific research performance in a higher education school. Performance of studies in higher education needs stability and long-term planning, but the results of the investigations shall not be "closed" only within the higher education school (Rabow et al., 2009). Therefore, the international dissemination of research results, which is related to the availability of scientific findings to scientific communities and the public, should be ensured (Pohoryles, 2002). The quality of research results and its dissemination inspire another academic mission of a scientist in a higher education school - cooperation with the public and partners by providing them with educational and research services. Higher education schools also provide education and research services to the interested business, community and government organizations. Business organizations may be interested in investing their capital into research provided by scientists, and scientists would be the research service providers in such a case (Pohoryles, 2002).

Social partners and academics working or acting together contribute to the execution of a higher education school's mission (Bart, 1998). So the missions of a researcher in a higher education school incorporate traditional teaching and research activities, as well as the cooperation activity with external participants or partners, which is characteristic of the contemporary postmodern society. In the context of contemporary society, these missions (teaching, research, social partnership) could be seen through the managerial skills where the scientist is approached as a service provider and developer.

Institutional level. Higher education schools (as well as business and profit organizations) formulate their mission, vision and strategic goals deploying administration departments for implementation, however, contribution of scientists working in higher education schools is also significant. 


\section{Acta Technologica Dubnicae \\ volume 5, 2015, issue 2}

Morphew \& Hartley (2006) have analysed 300 mission statements presented by USA higher education schools. The findings have revealed that each higher education school was trying to reflect upon the activities and institutional uniqueness as mission statements have described the activities and ambitions of the institutions. The scientists have indicated that about 80 percent of mission statements were systematically reviewed and updated. Wright (2002) has stated that 91 percent of framed missions were focused on the excellence, and only 40 percent reflected the reality.

Mission statements may be aimed at different target groups and a scientist is an important component of communication while implementing the mission of higher education school (Morphew \& Hartley, 2006). Mission statements of a higher education school also reflect the culture of the organization and its ideology, and scientists are broadcasting this culture to their closer or further environments (Feldner, 2006). Through such transmission of higher education school culture a scientist can convey the uniqueness and diversity of their higher education school among similar higher education institutions (Morphew \& Hartley, 2006) and their existence and activities at a higher education school reflect the institutional mission (Feldner, 2006). The formulated mission statements of a higher education school can be the inspiration for stakeholders and scientist who transmit the message properly to the environment serving as an attractor for investors (Velcoff \& Ferrari, 2006b; Bart, 1998). Acting as a member of the community, following the mission formulated by a higher education school, a scientist carries out the fourth - community developer's mission (Bart et. al., 2001).

Mission statements of specialized higher education schools declare the specific aims and objectives within their activity areas: the clinical (expertise) mission is mentioned by higher education schools in which physicians are trained (Joiner et al., 2008), and nursing or caring for patients and their relatives is the relevant mission of higher education schools in which nurses are trained (Karimbux \& Howell, 2004). The mission of specialized higher education schools is extended in conjunction with the specific activities of scientists in the particular research area.

Personal level. Personal responsibilities defining pedagogic, didactic, and research activities are presented in job descriptions of higher education schools though these documents do not focus attention on a scientist's mission. This phenomenon is also studied exceptionally rarely in educational and other researcher areas or spheres. In recent years, the scientific literature refers to several authors who have focused attention on universities and their personal mission analysis of academic staff.|

Rabow et al. (2009), Velcoff \& Ferrari (2006a, 2006b) have based the research results to indicate that the academic mission of a scientist basically consists of two components - professionalism and professional values that could be also 


\section{Acta Technologica Dubnicae \\ volume 5, 2015, issue 2}

internalized by students to the environment of higher education schools. Rabow et al. (2009), by examining the aspirations of the medical students and their expectations regarding learning in a higher education school, has revealed that one of the most important missions of a university professors (teachers) and scientists is to help students establish and strengthen their fundamental professional values. So, a scientist working at a university is a guardian and disseminator of professional values.

The personality of scientists must be coherent and integral with their functioning in higher education. According to Rabow et al. (2009), scientists must be of high moral character, altruist, responsible, dedicated to their activities in higher education school, honest, respectful for themselves and others. These values must be the essence of a scientist, but they also have to be transferred to students. The fundamental professional values of university scientists must be carried and spread through their granting of personal meanings to values and through their competence. Competence, ability to work accurately and professionally is also important to a scientist. Professionalism and competence are manifested through the proper application of general skills (development of relationships, communication, cooperation, emotion management, listening), but also through excellent knowledge of research (scientific) and professional field (Rabow et al., 2009).

Another mission of a scientist as an academic is the ability to act professionally or the professional identity on personal level. A scientist's work is manifested in three professional areas: professional knowledge and skills, personal qualities and skills, and professional identity arising through work experience. For a scientist, the expression of professionalism in practice through personal perception means to identify students' needs and implement them. The professionalism of a scientist is manifested in the ability to show the applicability of the research phenomena and objects in the real life (Velcoff \& Ferrari, 2006a). Researchers believe that personal involvement of every scientist in some of the activities of higher education school unit also shows the level of professionalism of a scientist and the ability to see the phenomena in the particular context (Velcoff \& Ferrari, 2006b). A scientist could be involved in the activities of a higher education school applying important personal aspects such as maintenance and dissemination of professional values in closed and/or distant environment. This is integral with the activity of a scientist which is the academic and intellectual. Acting in research and/or professional field a scientist has to come to terms with the activities and identify themselves in these activities. In other words, a scientist must act professionally and form (develop) own vocational (professional) identity allowing to become recognizable as a reliable professional and competent academic, and sophisticated intellectual. 


\section{Roles of a scientist in higher education: autonomous or interdependent?}

Academic staff at a higher education school, according to the attributed roles, performs various activities being associated with teaching and research, work in labour services, administration and human resources management. According to the distinguished roles and described activities diverging concepts exist how to handle the academic staff roles.

In one case it is emphasized that academic staff is focused on knowledge creation and transformation of knowledge being achieved through researchers' and teachers' roles (Romainville, 1996). Selected and/or assigned roles are carried out in response to the development and application of knowledge being associated with new ideas and discoveries, dissemination, application and even control. According to the assigned or provided roles, the execution of these roles contributes to the quality of disciplines, development and expansion of higher education schools and society (Arimato, 2009). In other case, the academic staff activities are split up into two areas - some activities are associated with carrying out investigations or research, teaching and learning, while other activities are related to leadership, administration and service provision (Condrad, 1998). This shows that the roles of a teacher and researcher remain the key ones in a higher education school, though scientists may also perform other roles related to management, administration, human resources, leadership, supervision and tutorship. Literature brings out complexity of the academic roles and a teacher or researcher represents traditional though axial roles. Other presumable roles could also be met by scientists in academic activities according to the specific situation (Dunkin, 2009). In summary, the main five roles were formulated, namely, a teacher, researcher, administrator or service staff, tutor and manager (see Figure 2). 


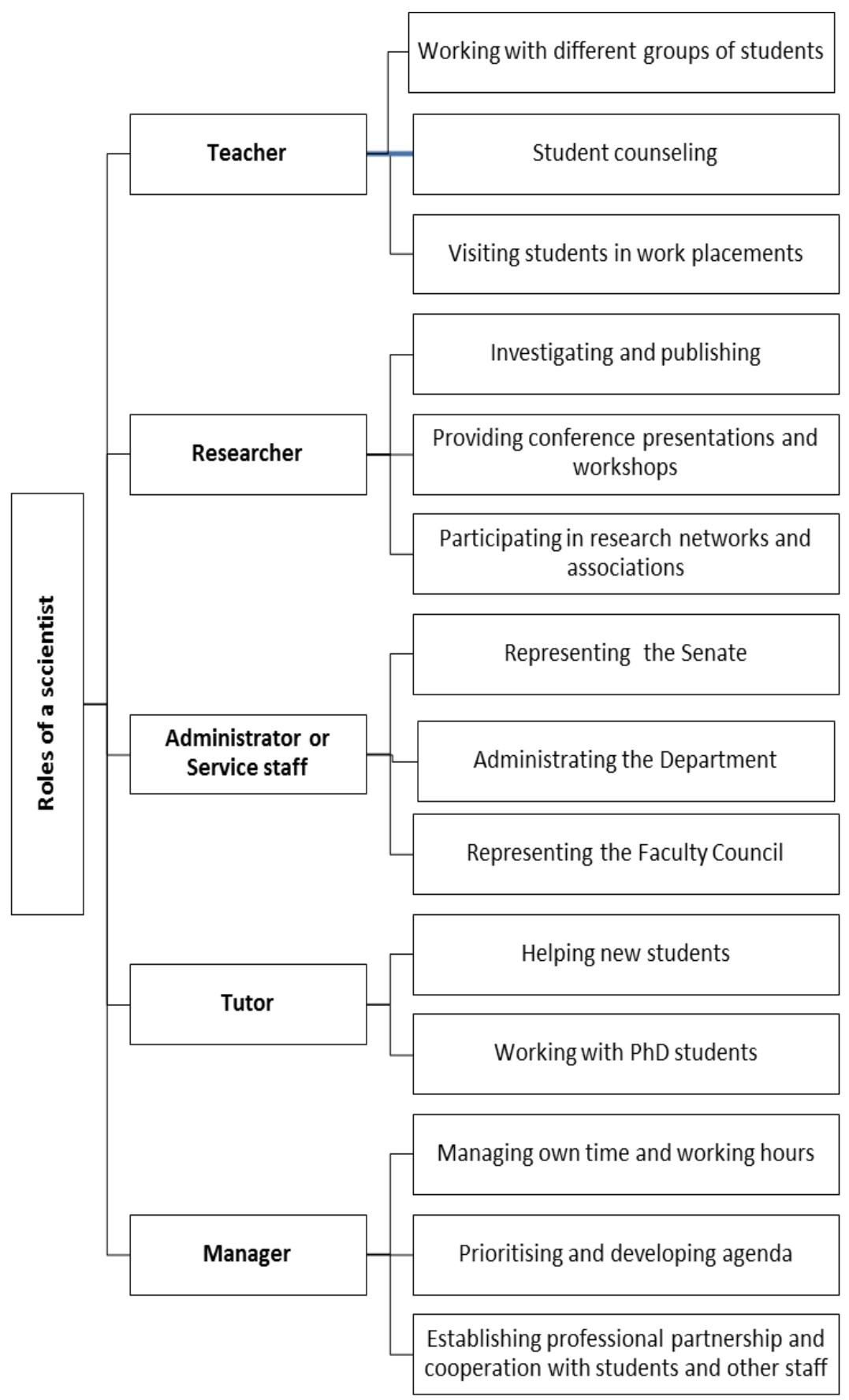

Figure 2. Roles of a scientist in a higher education school 


\section{Acta Technologica Dubnicae \\ volume 5, 2015, issue 2}

Discussing the role of a teacher, the contact with students, their counselling, transfer of knowledge and assessment of learning achievements are highlighted (Rowley, 1996). Knowledge and its transformation here are understood as basics for a teacher's role performance (Arimato, 2009). In this case, a dialogue with students and their support in knowledge construction are important, which leads not only to searching for new ideas, but the development of concepts and research of various phenomena (Brew, 2003; Bloch et al., 2012). However, it is difficult to assess the role according to the professional sense, as the role of a teacher is not recorded as a career and/or element of competition seeking for a higher academic degree or position. However, in terms of professionalism more attention is given to the depth of the studied research objects, the productivity investigator, strengthening a researcher's position within international networks, publication of research results and maintenance of the dialogue at international and national levels (Blaxter et al., 1998; Arimoto, 2009; Bloch et al., 2012). This shows that there is no clear differentiation between a teacher's and researcher's roles so far, thus the accumulated research knowledge is used during lectures and consultations. The absence of distinction contrasts a teacher's and a researcher's roles, because representatives of academic personnel usually call themselves a researcher rather than a teacher. In this case, it is easier to identify a researcher's role by triggering functions and competence and providing evidence of a scientist competence through the certificates of participation in conferences, articles in the scientific journals, participation in scientific debates and forums. Meanwhile, to provide the evidence regarding a teacher's competence in higher education is more difficult (Bloch et al., 2012).

Enders (1996) introducing the roles of academic staff notes that the juxtaposition of both a researcher and a teacher is impossible and leads to conflict. Cummings (2009) points out the complexity of these two roles and emphasizes professional autonomy, though, at the same time, argues that these two roles experience separation, and the main representative of a higher education school names the researcher. Also, the author points out that the German university model (as in Japan and Israel) attaches great importance to basic research. Meanwhile, the US university model emphasizes the importance of applied research. English university model experience shows that it is important to focus on teaching and keeping contact with students (Cummings, 2009). This comment shows that the culture of a higher education school defines the basis of the academic personnel's roles, and helps the member of the academic personnel to identify oneself clearly as a researcher or a teacher.

Enders \& Teichler (1997) have related administration staff roles to services and maintenance or attendance. However, there are concerns that academic staff roles (a teacher, researcher and administrative staff) which are related only in part or totally irrelevant by their nature, are often carried out by identical functions. On one hand, the knowledge system and the role of a teacher or the competence of a researcher are emphasized when the equivalent balance 


\section{Acta Technologica Dubnicae \\ volume 5, 2015, issue 2}

between these roles is observed. However, looking at the other side, a lot of attention is paid to research quality and functionality requiring consistent and methodological work orders. Administrational activities and permanent teaching are time consuming and interfere with the possibility to perform these roles consistently and effectively. Then in this case, the two roles are in contrast as a teacher is a service provider located next to the administration officer role.

Discussing the role of a tutor, supervision of doctoral students and research performance are highlighted (Senger, 2009). Arimato (2009) describes the role of a tutor and identifies it as one of the most important roles and being associated with education of young researchers, training of $\mathrm{PhD}$. students and their counselling. Scientists distinguish doctoral contexts where a supervisor is presented as a professional being capable to convey didactic framework involving the doctoral students into teaching within the certain phases (seminars, lectures, and consultations), communicating and cooperating with a doctoral student, helping to structure a doctoral program and conduct the investigation stages. The role of a tutor also includes counselling and interviewing newly admitted degree program students who need help and support at the very beginning of their studies. In this case, a tutor is increasingly seen as a helper (Wilcox et al., 2005). Students note that with the help of a tutor they were able to resolve outstanding issues, as the academic staff representatives note they lack time to chat with individual students and answer their questions. This is explained by the fact that scientists echo several roles at the same time being focused primarily on the role of a researcher or investigator and then a teacher (Wilcox et al., 2005).

Discussions referring to a manager's role usually point out time management, prioritizing of ongoing activities, planning the development and providing meetings with students and staff. The ability to coordinate activities, plan the work time and consultations with students, as well as distinguishing the priorities of the conducted activities is necessary (Rowley, 1996). The author indicates that the roles played by the academic staff can be grouped according to the similarities of functions performed and therefore distinguishes the following dyads: a lecturer and consultant, a researcher and promoter of publications, a conference participant and member of a working group, a manager and group leader, a counsellor and tutor. According to Dunkin (2009), academic staff responds to several roles at the same time depending on the situation. The author indicates a teacher and researcher accomplishing the main roles, and points out that a large part of a scientist's work consists of many other additional roles. These roles are the following: a tutor, demonstrator, writer, discoverer, designer, architect, investigator, expert, learner, developer, associate (contributor), agent, assistant, assessor or evaluator, critic, leader, colleague, supervisor, mentor, listener, counsellor, trainer, consultant, negotiator, manager, leader, businessman. In this case, it is important for a scientist to combine the roles and to plan the time and activities. 


\section{Acta Technologica Dubnicae \\ volume 5, 2015, issue 2}

Brockschnieder et al. (2009) has provided a competency model which includes academic staff roles in a higher education school and presents competencies referring to the groups (see Table 1). The vision of academic personnel as competent staff highlights the importance of knowledge referred to as the basis of the occupation together with a scientist's ongoing roles in a higher school (Arimoto, 2009). In this case, careful attention is concentrated on a scientist's academic productivity and creativity.

Table 1

Competencies of academic personnel in a higher education school (according to Marginson, 2000; Brockschnieder et al., 2009)

\begin{tabular}{|c|c|}
\hline $\begin{array}{l}\text { Blocks of } \\
\text { competencies }\end{array}$ & Abilities \\
\hline \multirow{4}{*}{$\begin{array}{l}\text { The } \\
\text { substantive } \\
\text { competencies }\end{array}$} & The ability to carry out investigations \\
\hline & The ability to plan and organize study process \\
\hline & The ability to create and manage projects in process \\
\hline & The ability to use ICT technologies \\
\hline \multirow{5}{*}{$\begin{array}{l}\text { General/key } \\
\text { competencies }\end{array}$} & The ability to apply strategic management techniques \\
\hline & The ability to manage planned activities \\
\hline & The ability to generate new ideas \\
\hline & The ability to solve problems with responsibility \\
\hline & $\begin{array}{l}\text { The ability to listen to different opinions and moderate } \\
\text { problems }\end{array}$ \\
\hline \multirow{5}{*}{$\begin{array}{l}\text { Social } \\
\text { competencies }\end{array}$} & The ability to communicate and collaborate \\
\hline & $\begin{array}{l}\text { The ability to form a team and work in an interdisciplinary } \\
\text { team }\end{array}$ \\
\hline & The ability to resolve conflicts \\
\hline & The ability to be empathic \\
\hline & $\begin{array}{l}\text { The ability to understand and recognize the diversity and } \\
\text { inter-culture }\end{array}$ \\
\hline \multirow{6}{*}{$\begin{array}{l}\text { Interpersonal } \\
\text { competencies }\end{array}$} & The ability to deal with ethical dilemmas \\
\hline & The ability to maintain strong values \\
\hline & The ability to remain authentic and exclusive \\
\hline & The ability to think critically and self-critically \\
\hline & The ability to communicate with experts in other fields \\
\hline & The ability to learn constantly \\
\hline
\end{tabular}




\section{Acta Technologica Dubnicae \\ volume 5, 2015, issue 2}

Different competencies or their blocks are important for academic staff working in different positions. It depends on the group being represented: young researchers, professors and the members of Dean's Office, Rector's Office or Senate. Depending on the situation and scientists' (academic personnel) positions, different competencies are relevant allowing to purify certain positions and not to distinguish so many activities (Dunkin, 2009). Scientific literature highlights the change of the concept of the 'scientist's role' as new challenges are raised for academic staff roles and more attention is paid to doctoral students' mentoring and education, their training and management of ongoing activities (Kogan \& Teichler, 2007).

\section{Conclusions}

The mission of a scientist is related to the multi-layered concept covering the roles, context, organizational structure and values in a higher education institution. It is essential for a scientist to perceive and define own mission(s), role(s), responsibilities and obligations to a higher education school, students, science, and society. The mission of a scientist in a higher education school rests in a certain combination of diverse competencies being applied on both organizational and individual levels. Thus the value such as trust is of great importance. A scientist's perception about their mission in a higher education school gives the meaning for the work. A scientist's working life is greatly enriched by making progress in scientific work through meaningful role performance. In other words, a scientist experiences mission performance or realization making the difference between the higher education context or area generally and in their research discipline specifically. Is the mission for a scientist so important? Finding own mission through the performance of particular role usually provokes a sense of discipline ownership in a higher education school. Then the scientific work implemented means something special and personal. When scientists undertake ownership of their academic work, they are more committed and intrinsically motivated or more engaged with their role performance at a higher education school.

In summary, academic staff roles are entwined and contrasting with each other. However, the roles of a researcher and teacher are linked in general as the role of a teacher requires accomplishing academic staff activities such as planning learning activities, devoting time for consultations, meetings and discussions with students. Although the role of a teacher is not indicated as the core one, however, it is often opposed to a role of a researcher where important activities refer to research performance and presentation of research results, as well as presentation of innovations for wider community. Comparison of the roles can be observed in both the dichotomy (a teacher and researcher roles complement each another) and the conflict, because the role of a teacher requires so much time and engagement in the learning process. A tutor's role is also released 


\section{Acta Technologica Dubnicae \\ volume 5, 2015, issue 2}

referring to the aid for a doctoral student and a scientist's leadership regarding the activities of doctoral students. The perception of academic staff roles of leaders and supervisors may be developed using available descriptions in scientific literature or institutional documents. Discussions on the management and administration roles should be concentrated on the capacities among which leadership, critical and analytical thinking, communication and intercultural abilities are emphasized. Although the roles of a teacher and researcher are mutually exclusive, it is evident that the boundaries between them are disappearing, and therefore the traditional concept of academic staff roles is also undermined. Though the roles being related to the administration and management of staff, students' and doctoral students' assistance and counselling are defined as short-term and fragmented - it gives value for the scientific discussions referring to scientist's leadership and supervision in higher education.

\section{Acknowledgements}

Financial support provided by the Research Council of Lithuania for the research and English language proof-reading is gratefully acknowledged

\section{References}

Arimoto, A. (2009). Changing Academic Profession in the World from 1992 to 2007. In The changing academic profession in international, comparative and quantitative perspectives (pp. 1-38). Hiroshima: Hiroshima University, RIHE Research Institute for Higher Education.

Bart, C. K. (1998). Mission Matters. CPA Journal, 68 (8), 56-57.

Bart, C. K., Bontis, N., \& Taggar, S. (2001). A model of the impact of mission statements on firm performance. Management Decision, 39 (1), 19-35.

Bloch, R., Würmann, C., \& Wittenberg, H. (2007). Außer Konkurrenz? Lehre und Karriere. Die Hochschule. Journal für Wissenschaft und Bildung Herausgegeben von Peer Pasternack für das Institut für Hochschulforschung (HoF) an der Martin - Luther Universität Halle Wittenberg, 1(2), 199-219.

Brinley, F. (2012). Surviving to Thriving: Advancing the Institutional Mission. Journal of Library Administration, 52 (1), 94-107.

Brockschnieder, S., Deckert, R., Klaus, G., Mehrtens, M., Senger, U., \& Thren, M. (2009) Konzeptioneller Rahmen für Personalentwicklung an Hochschulen. In Akademische Personalentwicklung (pp. 8-31). Essen: Verwaltungsgesellschaft für Wissenschaftspflege $\mathrm{GmbH}$.

Boud, D. (1990). Assessment and the promotion of academic values. Studies in Higher Education, 15 (1), 101-111. 


\section{Acta Technologica Dubnicae \\ volume 5, 2015, issue 2}

Brew, A. (2003). Teaching and Research: New relationships and their implications for inquiry-based teaching and learning in higher education. Higher Education Research \& Development, 22 (1), 3-18.

Conrad, L. (1998). Enhancing research through academic staff development. International Journal for Academic Development, 3 (2), 114-123.

Cummings, W. K. (2009). Teaching versus Research in the Contemporary Academy. RIHE International seminar reports, 13, September, 39-56.

Dunkin, R. (2009). Motivating knowledge workers: lessons to and from the corporate sector. Higher Education Management and Policy, 15(3), 41-49.

Elves, M. W. (2013). What is the scientist's role in society and how do we teach it? The Guardian. Retrieved from: http://www.theguardian.com/highereducation-network/blog/2013/nov/04/science-in-society-policy-research

Enders, J. (1996). Ausbildung, Beschäftigung und Karriere. Frankfurt/Main; New York: Campus Verlag.

Enders, J., \& Teichler, U. (1997) A victim of their own success? Employment and working conditions of academic staff in comparative perspective Higher Education, 34(3), 347-372.

Feldner, S. B. (2006). Living Our Mission: A Study of University Mission Building. Communication Studies, 57(1), 67-85.

Gordon, G. (2003). University roles and career paths: trends, scenarios and motivational challenges. Higher Education Management and Policy, 15(25), 91-92.

Grang, M. J., \& Booth, A. (2009). A typology of reviews. Health Information and Libraries Journal, 26(1), 91-108.

Houston, D. Meyer, L. H., \& Paewai, S. (2006). Academic Staff Workloads and Job Satisfaction: Expectations and values in academe. Journal of Higher Education Policy and Management, 28(1), 17-30.

Howell, T. H., \& Karimbux, N. Y. (2004). Academy: Strengthening the Educational Mission in Academic Health Centers. Journal of Dental Education, 68(8), 845-850.

Joiner, K. J., Libecap, A., Cress, A. E., Wormsley, S., Germain, P. S., Berg, R., \& Malan, P. (2008). Supporting the Academic Mission in an Era of Constrained Resources: Approaches at the University of Arizona College of Medicine. Academic Medicine, 83(9), 837-844.

Keyser, M. W. (2004). The academic mission and copyright law: are these values in conflict? escolarShare@drake. Retrieved from: http://escholarshare.drake.edu/handle/2092/250

Kogan, M., \& Teichler, U. (2007). Key Challenges to the Academic Profession and its Interface with Management: Some Introductory Thoughts (pp. 9-15). Paris \& Kassel: International Centre for Higher Education Research.

Klug, T. (2010). Professionelle Kompetenz für das Qualitäts- management in der Wissenschaft. Zeitschrift für Hochschulentwicklung, 5(4), 82-93. 
Kreber, C. (2010). How University Teaching Award Winners Conceptualise Academic Work: Some further thoughts on the meaning of scholarship. Teaching in Higher Education, 5(1), 61-78.

Mission. (n.d.). In Cambridge Advanced Learner's Dictionary \& Thesaurus. Retrieved from: http://dictionary.cambridge.org/dictionary/british/mission

Mission. (n.d.) In Collins English Dictionary. Retrieved from: http://www.thefreedictionary.com/mission

Mission. (n.d.). In Dictionary.com. Retrieved from: http://dictionary.reference.com/browse/mission

Mission. (n.d.). In MacMillan Dictionary. Retrieved from: http://www.macmillandictionary.com/dictionary/british/mission

Mission. (n.d.). In Meriam-Webster Dictionary. Retrieved from: http://www.merriam-webster.com/dictionary/mission

Mission. (n.d.). In Oxford Advanced Learner's Dictionary. Retrieved from: http://www.oxforddictionaries.com/definition/english/mission

Mission. (n.d.). In Random House Kernerman Webster's College Dictionary. Retrieved from: http://www.thefreedictionary.com/mission

Mission. (n.d.). In The Free Dictionary by Farlex. Retrieved from: http://www.thefreedictionary.com/mission

Marginson, S. (2000). Rethinking Academic Work in the Global Era. Journal of Higher Education Policy and Management, 22(1), 23-35.

Morphew, C. C., \& Hartley, M. (2006). Mission Statements: A Thematic Analysis of Rhetoric Across International Type. Journal of Higher Education, 77(3), 456-471.

Pohoryles, R. J. (2002). The European Research Area: Bureaucratic Vision versus Academic Mission? Innovation: The European Journal of Social Science Research, 15(4), 389-395.

Rabow, M., Wrubel, J., \& Remen, R. N. (2009). Promise of Professionalism: Personal Mission Statements among a National Cohort of Medical Students. Annals of Family Medicine, 7(4), 336-342.

Rowley, J. (1996). Motivation and academic staff in higher education. Quality Assurance in Education, 4(3), 1-16.

Schlüter, A., \& Winde, W. (2009). Konzeptioneller Rahmen für Personalentwicklung an Hochschulen. In Akademische Personalentwicklung (pp. 12-21). Essen: Stifterverband.

Senger, U. (2009). Personalentwicklung junger Forschender. In Akademische Personalentwicklung (pp. 32-66). Essen: Verwaltungsgesellschaft für Wissenschaftspflege GmbH.

Siegel, D. S., Wright, M., \& Lockett, A. (2007). The rise of entrepreneurial activity at universities: organizational and societal implications. Industrial and Corporate Change, 16(4), 489-504.

Tarquinio, G. T., Dittus, R. S., Byrne, D. W., Kaiser, A., \& Neilson, E. G. (2003). Effects of Performance-based Compensation and Faculty Track on 


\section{Acta Technologica Dubnicae \\ volume 5, 2015, issue 2}

the Clinical Activity, Research Portfolio, and Teaching Mission of a Large Academic Department of Medicine. Academic Medicine, 78(7), 690-701.

Velcoff, J., \& Ferrari, J. R. (2006a). Measuring Staff Perceptions of University Identity and Activities: The Mission and Values Inventory. Christian Higher Education, 5(3), 243-261. 